\title{
A Study of an Architecture Design Learning Process Based on Social Learning, Course Teaching, Interaction, and Analogical Thinking
}

\author{
Yun-Wu Wu, ${ }^{1}$ Chang-Fah Huang, ${ }^{2}$ and Kuo-Hua Weng ${ }^{3}$ \\ ${ }^{1}$ Department of Architecture, China University of Technology, Taipei 116, Taiwan \\ ${ }^{2}$ Department of Civil Engineering, National Kaohsiung University of Applied Sciences, Kaohsiung 807, Taiwan \\ ${ }^{3}$ Department of Interior Design, China University of Technology, Taipei 116, Taiwan \\ Correspondence should be addressed to Kuo-Hua Weng; ghwong@cute.edu.tw
}

Received 11 June 2014; Accepted 29 July 2014; Published 13 August 2014

Academic Editor: Teen-Hang Meen

Copyright ( 2014 Yun-Wu Wu et al. This is an open access article distributed under the Creative Commons Attribution License, which permits unrestricted use, distribution, and reproduction in any medium, provided the original work is properly cited.

\begin{abstract}
The students in the vocational education of architecture design in Taiwan often face many learning obstacles, such as no problem solving ability and lack of creativity. Therefore, this study used a social learning model as a learning strategy in the architecture design learning process to solve related learning difficulties. Firstly, this study used cognitive development teaching activities and a learning process based on analogical thinking and analogical reasoning to build the social learning model. Secondly, the social learning model of this study was implemented in the teaching of a required course of architecture design for 120 freshmen in China University of Technology. The questionnaire survey results were then statically analyzed and compared to measure the differences in the students' knowledge about architecture designs before and after the teaching in this study. In this study, the social learning model is proven helpful in inspiring the students' creativity by converting new knowledge of architecture design into schemas and hence retaining the new knowledge for future application. The social learning model can be applied in the teaching of architecture design in other schools, while more research can be conducted in the future to further confirm its feasibility to promote effective learning.
\end{abstract}

\section{Introduction}

The major purpose of this study is to establish an interactive learning model of architecture design based on social learning and analogical thinking that can provide guidance for students in their design implementation and help them solve difficulties in design learning. In addition, the model can evaluate students' effectiveness in learning by measuring the creativity in their learning results. Traditional architecture design courses in Taiwan are mainly based on the apprenticetype system like in traditional design studios. In this system, students receive limited time of guidance from their teachers. They often depend on their intuition or existing concepts (existing experiences, knowledge, and capability) to draw their design drafts. Then they submit their drafts to the teacher for review and comments and the teachers return the drafts to the students for revision. This process is repeated several times before the students produce their final designs. This trial-and-error learning method is both inefficient and ineffective for students to learn and cultivate their capability [1]. In addition, during the repetitive revisions, students may feel more confused and find it difficult to develop their design concepts on their own.

To promote learning efficiency, analogical materials were used as learning cases in this study to guide the students to discover the gap between their existing concepts and the concepts they were going to learn in the course. Then the students would become more motivated to learn and solve on their initiative the cognitive conflict caused by the gap. In addition, in the interactive learning in the classroom, the students were given the same design topics and learning methods and asked to have hand-on design operation in class so that the students could have the opportunities of learning from and discussing about each other's designs. 
In addition, the student could have more time interacting with the teacher in class. Through this interactive learning method, the students could not only improve their efficiency in creating their designs based on a socially-wise approach $[2,3]$ but also learn the concepts the teacher expected them to learn, build their schemas, and further enhance their design capabilities. In addition, through the teacher-student and student-student interactions and discussions, the creativity of the students could be inspired.

The goal of this study is to use the strategy of social learning and analogical thinking to help students to think and learn effectively through teacher-student and student-student interactions, expand their cognitive structures of cognitive design concepts, and develop the ability to flexibly use their knowledge of design concepts in their architecture designs so that they will be able to develop creative designs and know how to solve design problems on their own in the future.

\section{Literature Review}

2.1. Existing Problems in Architecture Design Education. In the design observation stage of existing architecture design courses, students are often found to be unable to understand the design topic and lack autonomous thinking. Therefore, it is difficult for them to feel motivated in learning and they are prone to implement their designs via trials and errors. With their existing concepts conflicting with the design objectives, students cannot develop solutions to their design problems. Therefore, Duit proposed the use of analogies to better motivate students [4]. In analogical thinking, familiar contexts are used to motivate students to find out problems on their own, revise and reconstruct the characteristic elements of their designs, fill the gap between their existing concepts and the concepts they are learning, and ultimately solve their design problems.

2.2. Social Learning. Bandura believed that learning is a lasting process of behavior changes through experiences and practices [5]. It is subject to the influence of the continuous interactions between an individual and his/her social environment. The behaviors of humanity are acquired mostly through learning. Since birth, an individual has been constantly and unconsciously learning the behaviors of others and then gradually become a member accepted by the family and society. Therefore, Bandura proposed the concept of triadic reciprocity, stressing that an individual could acquire certain response behaviors through learning. Learners first observe an object or an incident, learn how to respond to the object or incident based on their own thoughts and past experiences (external environment), and then attain what they have learned in their memories (cognition). A learner's behavior or performance is the reflection of what he or she has learned. When encountering an identical or similar incident (external stimulation), they will take the same behavior (action) in response. The series of learning activities all involve external stimulation, and, therefore, it is called "social learning," a major channel for each individual to learn social behaviors.

\subsection{Interaction}

2.3.1. Teacher-Student Interaction: Using Suitable Teaching Materials and Methods to Guide Students in Their Learning. Vygotsky believed that learners are subject to the influence from the external environment, that is, social (interpersonal interaction) environment [6]. He stressed that rich social and cultural contents will influence the cognition of learners. He also believed that elders and peers with more experiences can help learners to internalize new knowledge into the foundation of their knowledge. The influence of the external environment is particularly significant when people are learning a language. With better language skills and knowledge, one will become more capable of communicating with others, which will lead to a series of continuous changes in his or her thinking and behaviors. Such changes vary significantly among different individuals due to their personal and cultural differences. Therefore, the development of cognition can also be seen as a process of social adjustments.

2.3.2. Student-Student Interaction: Increasing the Opportunity of Growth for Students through Mutual Discussions and Learning. According to the theory of social learning, a learning process can be mainly divided into two stages: observational learning and imitation.

(1) Observational learning: according to Bandura and Adams [7], observational learning is composed of four phases: attentional phase, retention phase, reproduction phase, and motivational phase.

(2) Imitation: based on different psychological demands of the learners and the skills or concepts they want to learn, there are four methods of imitation: direct modeling, synthesized modeling, symbolic modeling, and abstract modeling. By imitating the essence or strengths in the existing works or solutions developed by others, learners can reduce the time required for trials and errors and then find some effective and feasible solutions.

In the process of social learning, students can learn from each other through mutual observation and mutual critiques and they can incorporate what they learn to adjust their own designs. Through the interactions between their external exchanges with classmates and their internal cognition, students can learn more new knowledge. When solving their design problems, students can interact with their classmates through discussions and exchanges of their experiences, results, and problems. Through this method, students can develop the capabilities of thinking critically and innovatively, finding the fundamental causes of problems, seeking methods of improvement, and creating more diversified solution policies. Therefore, learning interaction is a very effective learning tool to enhance students' design competence.

2.4. Teaching Implementation. The focus of this research is to promote the students' understanding and development of their own design concepts by incorporating analogical 
learning as the fundamental teaching method in the course. Furthermore, a learning model based on bridging analogies is developed to replace the learning model based on simple analogies in order to improve the students' learning results. The analogical thinking in the study is used in the students' social learning process of observation, discovery, knowledge construction, knowledge application, and knowledge storage.

In the teaching based on analogical thinking, a set of related cases, anchor cases, and cases of bridging analogies [8-10] are given to the students to observe and inspire them to think and learn. Then, the teacher selects and arranges related questions and issues for the students to have open discussions in class. The teacher is responsible for clearly indicating the design learning goals, guiding and encouraging the students to have discussions, and inspiring the students to analyze the connections among the design learning goals, anchor cases, and analogical cases.

The main goal of using analogical thinking in the teaching of this study is to promote interactions between the students' existing concepts (experiences) and new concepts. The students can then assimilate and internalize the new concepts they learn into their existing knowledge systems so that the new concepts can be stored in their long-term memories to form new schemas. Through the interactions between the students' existing concepts and their cognitive reasoning capabilities, the students will be able to apply the knowledge they learn in their designs.

2.5. Analogical Thinking. Generally, traditional architectural courses mostly focus on cognition of lower levels. In addition, the teaching in these courses was very simplistic; therefore, students suffer from great difficulties in transferring the concepts they learn in class into complicated real-life contexts. In addition, students are not motivated to learn or think on their initiative. As a result, it is very difficult for students to find inspirations from their learning. Last but not least, because of the apprentice type teacher-student interaction model in traditional architecture design courses, students have to learn through trials and errors. After too many trials and errors, students will feel frustrated and unmotivated to learn. According to Nersessian [11], analogical reasoning is the key step of inspiration in many scientific explorations. Analogical thinking can help students to find out problems on their own, stimulate their abstract thinking, help them to develop their concepts, categorize the component elements of their designs, and form their knowledge systems based on a series of related cognitive contents.

With unclear understanding of the design objectives and also with interferences from their existing concepts, students are too confused to think logically, let alone solving their design problems. In traditional architecture design learning, there is no efficient guidance for students. The evaluation of the students' performance is solely based on their design drawings, while the students cannot accumulate valid design concepts. Analogical reasoning can help to solve confusion [12] and can help students to develop the principles of abstract concepts [9].
If students completely lack critical thinking and systematic knowledge about design concepts such as design units, constructs, and themes, it is very difficult to expect them to develop design creativity based on the system of their existing knowledge. Analogies can help students to develop critical thinking [13] and analogical thinking is one of the effective models of creative thinking [14]. Creative thinking requires a good knowledge organization structure so that knowledge can be stored and transferred flexibly to look for connections between knowledge of different fields [15]. Creative thinking can be used to make policies to meet the design objectives and produce creative designs.

In conclusion, in traditional architecture design courses, students are often unable to understand the design objectives and are lacking in learning motivation because of the inefficient trial-and-error learning process. With analogical learning, students are more motivated to learn and solve cognitive conflicts between their existing knowledge and the new knowledge they are learning [16]. The new knowledge is then internalized into the student's knowledge system and used to produce creative designs. Through analogical learning, the goal of architecture design talent cultivation can be met.

\section{Research Framework}

3.1. Samples. The samples in this study were totally 120 dayschool freshmen of the Department of Architecture on the Taipei Campus of China University of Technology. They all took the course of "Architecture Design (I): 3D Combination of Visual Components," a required course for the freshmen in the Department. In this course, analogical thinking was incorporated into the teaching to help the students complete their designs through work sharing, teacher-student interactions, student-student interactions, and self-reflection.

3.2. Learning Model. The interactive learning model based on social learning, course teaching, and analogical thinking is composed of analogical learning (observation and discovery) and analogical reasoning (knowledge construction and application). There are three dimensions in this model: course teaching, interaction, and analogical thinking. The structure of this model is illustrated in Figure 1.

3.3. Experiment Implementation. The experiment in this study was conducted in the teaching of the "Architecture Design (I): 3D Combination of Visual Components" course to measure the effectiveness of the learning model.

3.3.1. Week 1: Social Learning-Observation-Assimilation-Existing Concept. In this week, the design topic and analogical cases were given and explained to attract attention from the students. In the course teaching, activities were given to encourage the students to take the initiative of learning, focus their attention on important concepts, and screen out irrelevant information.

(1) Course teaching: in this week, the design topic was announced and explained in the course. In addition, 


\begin{tabular}{|c|c|c|c|c|c|c|}
\hline \multicolumn{7}{|c|}{ The model of architecture design learning process based on social learning, course teaching, interaction, and analogical thinking } \\
\hline \multicolumn{2}{|c|}{ Construct } & Observation & Discovery & Construction & Application & Storage \\
\hline \multicolumn{2}{|c|}{$\begin{array}{l}\text { Learning } \\
\text { history }\end{array}$} & Week 1 & Week 2 & Week 3 & Week 4 & Week 5 \\
\hline \multirow{2}{*}{ 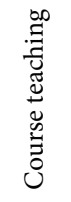 } & $\begin{array}{l}\text { Teaching } \\
\text { goal }\end{array}$ & $\begin{array}{l}\text { Stimulating } \\
\text { learning thinking }\end{array}$ & $\begin{array}{l}\text { Inducing } \\
\text { learning motivation }\end{array}$ & $\begin{array}{l}\text { Ability of problem } \\
\text { reasoning and solving }\end{array}$ & $\begin{array}{l}\text { Design concept } \\
\text { establishment }\end{array}$ & $\begin{array}{c}\text { Ability of } \\
\text { critical thinking }\end{array}$ \\
\hline & $\begin{array}{l}\text { Teaching } \\
\text { material }\end{array}$ & Analogical case & $\begin{array}{l}\text { Analogical bridge case } \\
\text { past students' works }\end{array}$ & $\begin{array}{l}\text { Students' works } \\
\text { draft }\end{array}$ & $\begin{array}{l}\text { Students' works } \\
\text { draft }\end{array}$ & Students' final works \\
\hline \multirow{2}{*}{ 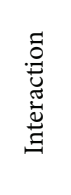 } & Activities & $\begin{array}{l}\text { Design work } \\
\text { requirement released }\end{array}$ & $\begin{array}{l}\text { Observation } \\
\text { discussion }\end{array}$ & Peer discussion & Peer discussion & Teacher assessment \\
\hline & Assignment & $\begin{array}{l}\text { Concept } \\
\text { (draft 1) }\end{array}$ & $\begin{array}{l}\text { Basic design } \\
\quad(\text { draft } 2)\end{array}$ & $\begin{array}{l}\text { Initial design } \\
\quad(\text { draft } 2)\end{array}$ & $\begin{array}{l}\text { Detail design } \\
\quad \text { (work) }\end{array}$ & Work report \\
\hline \multirow{2}{*}{ 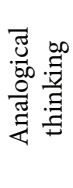 } & $\begin{array}{c}\text { Concept } \\
\text { development }\end{array}$ & $\begin{array}{l}\text { Concept } \\
\text { breeding }\end{array}$ & $\begin{array}{l}\text { Concept } \\
\text { formation }\end{array}$ & $\begin{array}{c}\text { Concept } \\
\text { development }\end{array}$ & $\begin{array}{l}\text { Concept } \\
\text { application }\end{array}$ & The rule of thumb \\
\hline & $\begin{array}{l}\text { Concept } \\
\text { transfer }\end{array}$ & $\begin{array}{l}\text { Assimilation- } \\
\text { pre-existing concept }\end{array}$ & $\begin{array}{l}\text { Assimilation- } \\
\text { cognitive conflict }\end{array}$ & $\begin{array}{l}\text { Accommodation- } \\
\text { learning concept }\end{array}$ & $\begin{array}{c}\text { Accommodation- } \\
\text { knowledge construction }\end{array}$ & Scheme \\
\hline & Construct & Analogi & learning & & Analogical reasoning & \\
\hline
\end{tabular}

FIGURE 1: Structure of the learning model developed in this research (Source: compilation of this study).

the paintings by Mondrian and Kandinsky were provided as analogical cases to guide the students in discovering problems, stimulate their abstract thinking, and consequently help them to develop their design concepts.

(2) Interaction: the teacher spent one to two hours explaining the design topic and teaching goals, analyzing the analogical cases to guide the students in finding the problems, ask them to decompose and extract the characteristic elements in the paintings, and inspire them to develop concepts for their first drafts by using analogical references from the paintings.

(3) Analogical thinking: the paintings by Mondrian and Kandinsky were used as analogical cases for the students to extract design elements from the paintings as analogies for their development of design concepts.

\subsubsection{Week 2: Social Learning-Discovery-Assimilation-Cogni-} tive Conflict. In this week, actual design cases and the assignments of a former student in this course were used as an example to guide the students in their learning of new design concepts. Through their observation and adjustment, the students started to integrate the new knowledge with their existing knowledge.

(1) Course teaching: the concept of bridging analogies was applied and the students were provided with more analogical cases that had reasonable similarities with the problems the students needed to solve. With the gaps between the analogical cases and the students' design concepts, cognitive conflicts were caused and, therefore, the students were motivated to learn and think about how to narrow these gaps.

(a) Teaching based on bridging analogies. In this week, an actual design case (Figure 2) was used to illustrate how bridging analogies could help to produce new works through the process of concept conversion (Figure 3) [17].

(b) Teaching based on analogical cases. The design by a student (hereinafter referred to as Student A) who took the same course in 2012 was used as an analogical case. Student A chose the work, Place de la Concorde, by Mondrian as the inspiration for his analogical thinking and produced his first draft (Figure 4), second draft (Figure 5), third draft (Figure 6), and final design (Figure 7) in the end. The example of Student A was used to illustrate the design process based on analogical learning.

(2) Interaction: in the class, the teacher provided corresponding cases and helped the students to complete their second draft by showing them how to extract design elements such as materials, colors, and constructs from the cases. In addition, the students also discussed and analyzed together the cases they collected and then compared the cases with their own drafts to better understand the meanings of the design concepts and revise their drafts accordingly. 


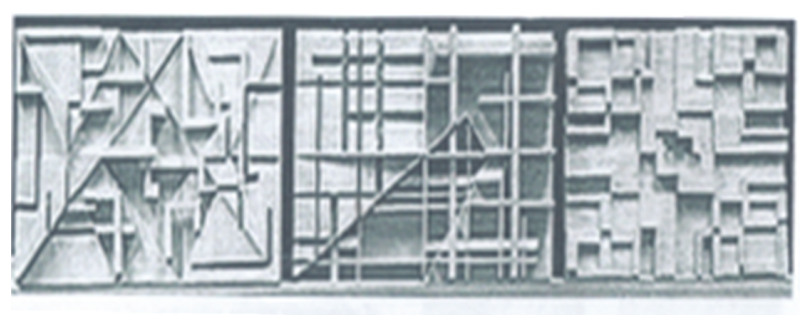

FIGURE 2: (Source: [17]).
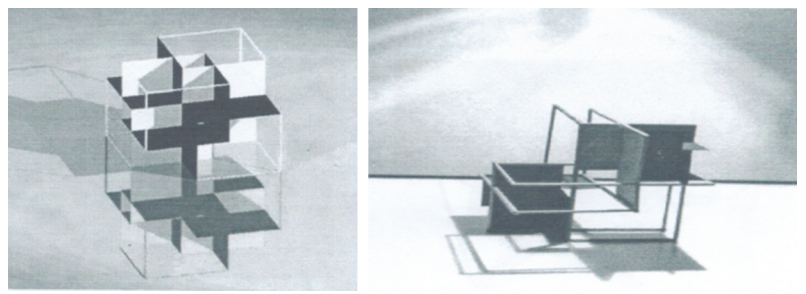

FIGURE 3: (Source: [17]).

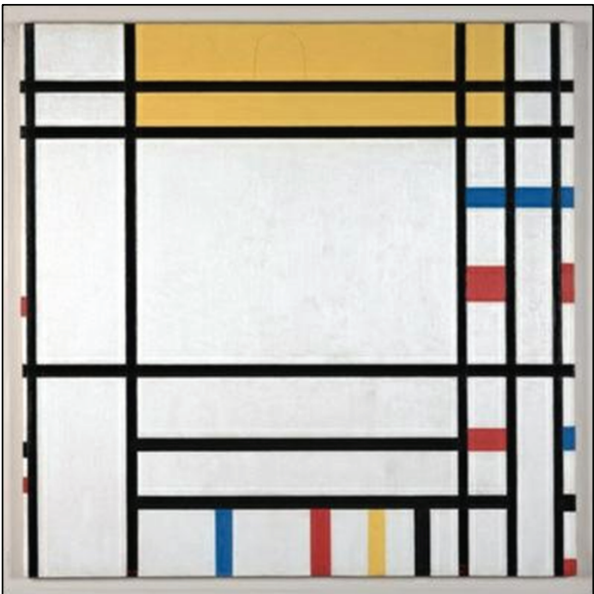

Figure 4: Draft I-concept conception.

(3) Analogical thinking: in this stage, the students were processing new concepts based on their existing concepts. By comparing and discussing their own concepts and the cases of bridging analogies (Figures 4, 5, 6, and 7), the students were trying to merge the new knowledge and their existing knowledge. When the merging failed, a cognitive conflict would occur for the students. Piaget believed that learners have their internal motivation of learning and, therefore, he proposed the theory of equilibration. According to the theory, a cognitive conflict (or disequilibrium) is caused when there is inconsistency between the learners' newly learned skills/knowledge and their existing cognitive systems. Under such circumstances, the learners will solve the conflict on their own initiative in order to restore the previous equilibrium and internalize the new skills/knowledge without any necessity of external motivation. Therefore, the occurrence of cognitive conflicts will help to motivate students to learn and discover problems on their own in the process of analogical learning and ultimately help them to develop their design concepts.

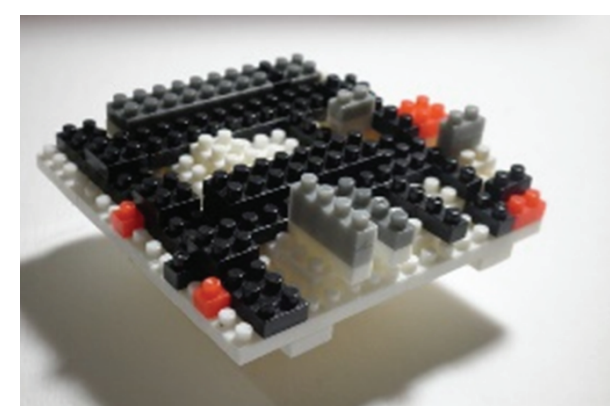

Figure 5: Draft II—concept formation.

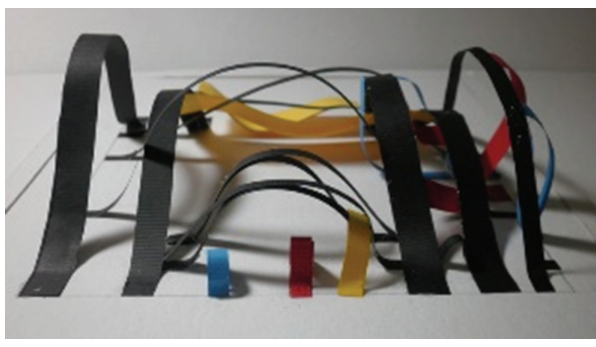

FIGURE 6: Draft III—concept development.

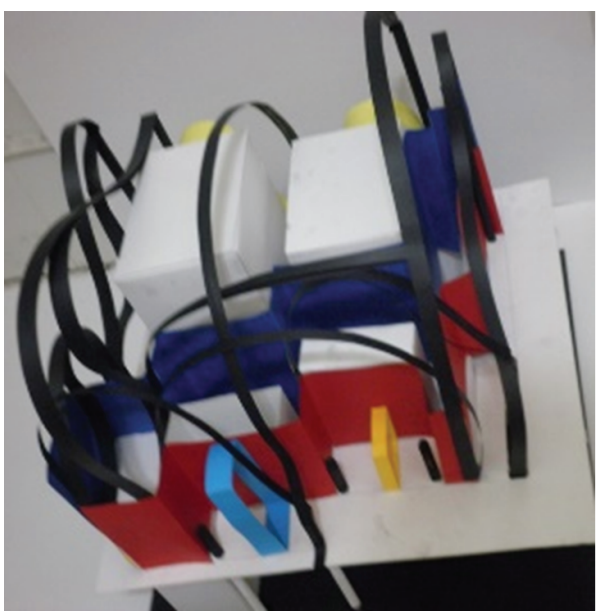

Figure 7: Final design—concept application.

3.3.3. Week 3: Social Learning-Construction-AdjustmentLearning Concept. In this week, the teacher helped the students to adjust the connections between their existing knowledge and new knowledge, establish their new cognitive structures, and use the new knowledge in their designs.

(1) Course teaching: the theory of social construction not only stresses the knowledge construction of individuals but also inspires students to generate creative thinking through the observation and interaction activities in class for they are motivated with the resources and support from the interactions with their teachers and classmates to overcome challenges. According to Nersessian [11], analogies cannot only 
help to guide learning but also promote logical reasoning to solve problems. Therefore, analogical reasoning is a pivotal step in many scientific explorations. In this week, the students were asked to observe each other's work and offer their critiques in order to guide them in their development and revision of design concepts and help them cultivate capabilities of logical reasoning and problem solving.

(2) Interaction: in this stage, the students started to build $3 \mathrm{D}$ construction of their designs using the extracted design elements and develop their own analogies from the cases they collected. This arrangement could help the students to connect the new knowledge with their existing knowledge and experiences. In addition, the students could develop better understanding of the connections between the analogical cases and their design concepts and then had more effective analogical transfers that could help them complete their drafts.

(3) Analogical thinking: through the discussions as well as mutual observation, learning, and critiques about their drafts, the students would encounter certain levels of cognitive conflicts. In the process of existing cognitive equilibrium, disequilibrium, and then reequilibrium, the students started to develop their own learning concepts. In addition, through knowledge assimilation and adjustment, they changed their understanding about architecture design concepts, integrated the assimilated new knowledge into suitable positions in their cognitive structures, and then efficiently developed their design concepts.

3.3.4. Week 4: Social Learning-Application-AdjustmentKnowledge Construction. In this week, the students were guided to compare their existing concepts and the new concepts and then express their internalized new knowledge in their designs.

(1) Course teaching: the teacher helped the students to develop systematic knowledge about design concepts such as design units, constructs, and themes by asking the students to observe each other's work and offer mutual critiques. Concepts were extracted from analogical cases to produce creative designs that could meet the requirements of the design topic in class.

(2) Interaction: the students observed each other's semifinal drafts and models and also offered mutual critiques. Analogical learning could help the students to develop principles about abstract concepts [9] and build their design concepts, knowledge, thinking, action, and capability.

(3) Analogical thinking: in this stage, the students had gradually developed further understanding about the essence of design concepts and started to achieve their cognitive reequilibrium. By continuously adjusting to the environment and new concepts and developing new knowledge, the students learned how to use their concepts flexibly to complete their designs, improve their thinking and problem-solving capabilities, and establish their design concepts.

3.3.5. Week 5: Social Learning-Storage Schema. In this week, the students stored the design concepts and knowledge they had learned from the analogical cases and turned the new concepts and knowledge into their knowledge for the use in their new designs in the future.

(1) Course teaching: by evaluating the students' designs, the teacher could understand their learning results, analyze their cognitive development of architecture design concepts, help them to cultivate the capabilities of critical thinking and concept application, and prepare them for more advanced courses of architecture design.

(2) Interaction: the teacher started to evaluate the students based on their learning reviews and reports. Before the formation of their design concepts, the students were completely unable to have critical thinking. The use of analogical thinking in the evaluation of the students' learning results could help the students to develop critical thinking [13]. The teacher and the students had critical reviews of the design works by some of the students in order to achieve the goal of design review.

(3) Analogical thinking: all the information units are stored closely together in a part of human memory. This part of human memory is called a schema. It is a structure of data stored in human memory and represents the prototype of general concepts [18]. After receiving information from the external environment, people will process the information by retrieving related memories from the lower schemas in their knowledge schema structures and then the processed results will be sent to the higher schemas. Schemas are the building blocks of cognition, allowing people to understand knowledge and experiences through categorization. Through analogical thinking and learning, the students were guided to develop their design concepts, store their experiences in their long-term memories, develop critical thinking, expand their schema structures of architecture design knowledge, and have better command of design concepts.

\section{Questionnaire Analysis}

In this study, social learning, course teaching, interactive learning, and analogical thinking were integrated in the teaching of architecture design. In the observation and discovery stages, the students in this study learned new knowledge analogically from existing cases under the teacher's guidance. In the construction and application stages, the students completed their designs and effectively improve their design problem-solving capability from their interactions with both the teacher and their peers. In addition to the teaching experiment, a questionnaire survey was also 
TABLE 1: Statistical analysis results of the questionnaire survey on the students' pretest and posttest scores.

\begin{tabular}{|c|c|c|c|c|c|c|}
\hline \multicolumn{2}{|l|}{ Social learning } & Average & Standard deviation & Degree of freedom & $t$ & Significance \\
\hline \multirow{2}{*}{ Observation } & Pretest & 21.08 & 3.71 & \multirow{2}{*}{103} & \multirow{2}{*}{$-11.43^{* *}$} & \multirow{2}{*}{0.000} \\
\hline & Posttest & 24.80 & 3.18 & & & \\
\hline \multirow{2}{*}{ Discovery } & Pretest & 6.45 & 1.40 & \multirow{2}{*}{103} & \multirow{2}{*}{$-11.73^{* *}$} & \multirow{2}{*}{0.000} \\
\hline & Posttest & 8.06 & 1.19 & & & \\
\hline \multirow{2}{*}{ Construction } & Pretest & 6.41 & 1.60 & \multirow{2}{*}{103} & \multirow{2}{*}{$-10.57^{* *}$} & \multirow{2}{*}{0.000} \\
\hline & Posttest & 7.96 & 1.19 & & & \\
\hline \multirow{2}{*}{ Application } & Pretest & 6.88 & 1.43 & \multirow{2}{*}{103} & \multirow{2}{*}{$-9.09^{* *}$} & \multirow{2}{*}{0.000} \\
\hline & Posttest & 8.11 & 1.04 & & & \\
\hline \multirow{2}{*}{ Overall learning performance } & Pretest & 40.82 & 6.60 & \multirow{2}{*}{103} & \multirow{2}{*}{$-13.48^{* *}$} & \multirow{2}{*}{0.000} \\
\hline & Posttest & 48.92 & 5.66 & & & \\
\hline
\end{tabular}

${ }^{* *} P<0.01$

conducted in this research to evaluate the students' learning results before and after the teaching experiment.

The statistical analysis results of the questionnaire results in this study are shown in Table 1.

4.1. Observation Stage. As indicated in Table 1, the average posttest score of the students $(M=24.80)$ in the observation stage is higher than their average pretest score $(M=21.08)$. The $t$ value between the pretest and posttest average scores is $-11.43(P=0.000)$, which reaches the level of significance $(<0.05)$ with a degree of freedom at 103 . This indicates significant differences in the students' pretest and posttest average scores in the observation stage, suggesting the students find their observation of cases under the teacher's guidance very helpful for their learning of architecture design.

4.2. Discovery Stage. As indicated in Table 1, the average posttest score of the students $(M=8.06)$ in the discovery stage is higher than their average pretest score $(M=6.45)$. The $t$ value between the pretest and posttest average scores is $-11.73(P=0.000)$, which reaches the level of significance $(<0.05)$ with a degree of freedom at 103. This indicates significant differences in the students' pretest and posttest average scores in the discovery stage, suggesting the students find their observation of cases under the teacher's guidance very helpful for their learning of architecture design and that the students find their analogical thinking under the teacher's guidance helpful for their learning of architecture design by extracting elements from the cases.

4.3. Construction Stage. As indicated in Table 1, the average posttest score of the students $(M=7.96)$ in the construction stage is higher than their average pretest score $(M=6.41)$. The $t$ value between the pretest and posttest average scores is $-10.57(P=0.000)$, which reaches the level of significance $(<0.05)$ with a degree of freedom at 103 . This indicates significant differences in the students' pretest and posttest average scores in the construction stage, suggesting that the students believe that they can analyze and extract elements and constructs from their classmates' designs from their interactions and discussions with their classmates and then incorporate these elements and constructs in both their schemas and designs.

4.4. Application Stage. As indicated in Table 1, the average posttest score of the students $(M=8.11)$ in the observation stage is higher than their average pretest score $(M=6.88)$. The $t$ value between the pretest and posttest average scores is $-9.09(P=0.000)$, which reaches the level of significance $(<0.05)$ with a degree of freedom at 103 . This indicates significant differences in the students' pretest and posttest average scores in the application stage, suggesting that, from their analogical learning, the students learn how to extract the elements and constructs from their own schemas or cognitive structures for their future designs.

4.5. Overall Learning Performance. As indicated in Table 1, the students' average posttest score $(M=48.92)$ is higher than their average pretest score $(M=40.82)$ and the $t$ value between the pretest and posttest score averages is $-13.48(P=$ $0.000)$, which reaches the level of significance $(<0.05)$ with a degree of freedom at 103 . These findings indicate the students had significant improvement in their learning of architecture design after their social learning.

\section{Conclusion}

In the experiment of this study, the students learned about architecture design through a learning process based on social learning, course teaching, interaction, and analogical thinking to gradually develop their own cognitive concepts of architecture design and convert their new knowledge into new schemas that were then stored in their long-term memories and became part of their cognitive structures. Their new knowledge helped the students to develop better design reasoning and creativity. This study confirms the feasibility of using analogical thinking in the teaching of architecture design. Follow-up research in the future is suggested to not only focus on interactions in teaching but also to conduct questionnaire surveys and statically analyze the survey results to further evaluate the effectiveness of analogical thinking in learning. 


\section{Conflict of Interests}

The authors declare that there is no conflict of interests regarding the publication of this paper.

\section{Acknowledgment}

The funding of this research work is provided by the National Science Council, Taiwan, under grant NSC 102-2511-S-163002.

\section{References}

[1] D. A. Schon, Educating the Reflective Practitioner. Toward a New Design for Teaching and Learning in the Professions, The Jossey-Bass Higher Education Series, Jossey-Bass Publishers, San Francisco, Calif, USA, 1987.

[2] K. Budge, "Art and design blogs: a socially-wise approach to creativity," International Journal of Art and Design Education, vol. 31, no. 1, pp. 44-52, 2012.

[3] B. Matthews and T. Heinemann, "Analysing conversation: studying design as social action," Design Studies, vol. 33, no. 6, pp. 649-672, 2012.

[4] R. Duit, "On the role of analogies and metaphors in learning science," Science Education, vol. 75, no. 6, pp. 649-672, 1991.

[5] A. Bandura, "Social learning theory of aggression," Journal of Communication, vol. 28, no. 3, pp. 12-29, 1978.

[6] L. S. Vygotsky, "The development of higher psychological functions," Russian Social Science Review, vol. 18, no. 3, pp. 38-51, 1977.

[7] A. Bandura and N. E. Adams, "Analysis of self-efficacy theory of behavioral change," Cognitive Therapy and Research, vol. 1, no. 4, pp. 287-310, 1977.

[8] D. Gentner, "Structure-mapping: a theoretical framework for analogy," Cognitive Science, vol. 7, no. 2, pp. 155-170, 1983.

[9] J. Clement, "Using bridging analogies and anchoring intuitions to deal with students' preconceptions in physics," Journal of Research in Science Teaching, vol. 30, no. 10, pp. 1241-1257, 1993.

[10] T. Bryce and K. MacMillan, "Encouraging conceptual change: the use of bridging analogies in the teaching of action-reaction forces and the "at rest" condition in physics," International Journal of Science Education, vol. 27, no. 6, pp. 737-763, 2005.

[11] N. J. Nersessian, "How do scientists think? Capturing the dynamics of conceptual change in science," Cognitive Models of Science, vol. 15, pp. 3-44, 1992.

[12] J. S. Brown, A. Collins, and P. Duguid, "Situated cognition and the culture of learning," Educational Researcher, vol. 18, no. 1, pp. 32-42, 1989.

[13] J. L. Middleton, "Student-generated analogies in biology," The American Biology Teacher, vol. 53, no. 1, pp. 42-46, 1991.

[14] U. Goswami, Analogical Reasoning in Children, Psychology Press, 1992.

[15] L. R. Novick and C. E. Hmelo, "Transferring symbolic representations across nonisomorphic problems," Journal of Experimental Psychology: Learning, Memory, and Cognition, vol. 20, no. 6, pp. 1296-1321, 1994.

[16] Y. Wu and $\mathrm{K}$. Weng, "Using an analogical thinking model as an instructional tool to improve student cognitive ability in architecture design learning process," International Journal of Technology and Design Education, vol. 23, no. 4, pp. 1017-1035, 2013.
[17] K. A. Liapi, "Geometry in architectural engineering education revisited," Journal of Architectural Engineering, vol. 8, no. 3, pp. 80-88, 2002.

[18] D. E. Rumelhart and D. A. Norman, "Analogical processes in learning," Cognitive Skills and Their Acquisition, pp. 335-359, 1981. 


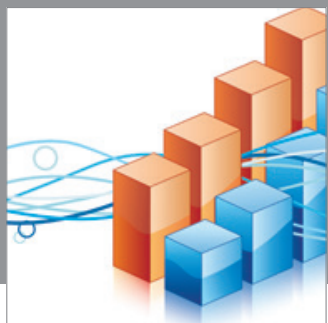

Advances in

Operations Research

mansans

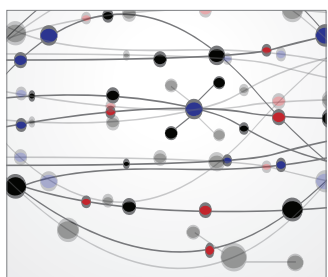

The Scientific World Journal
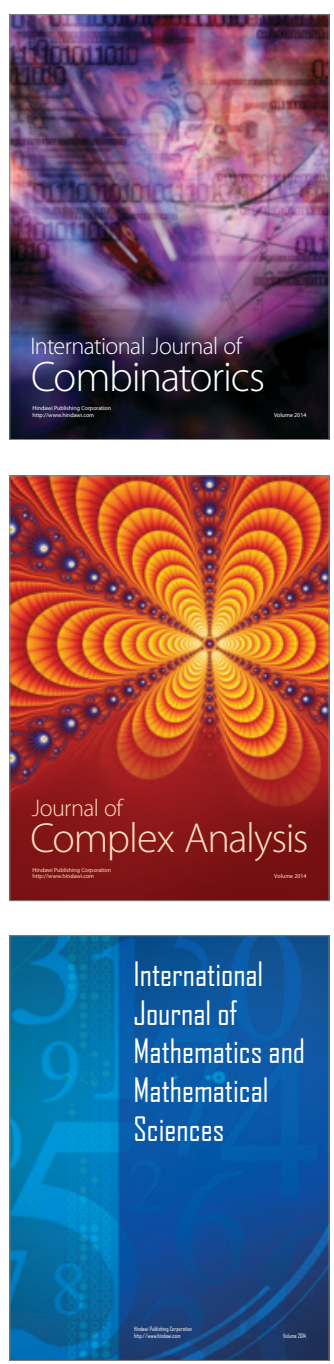
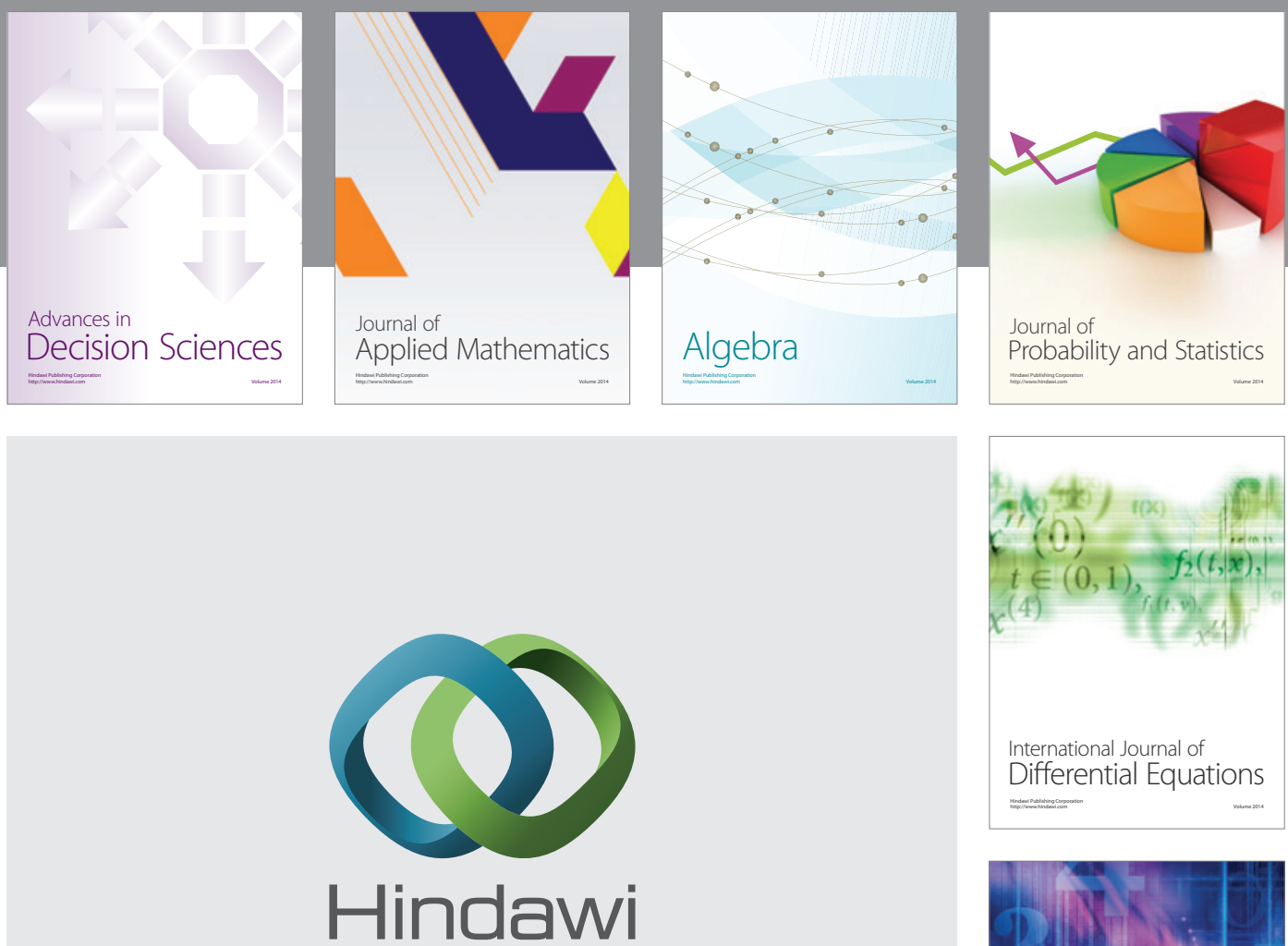

Submit your manuscripts at http://www.hindawi.com
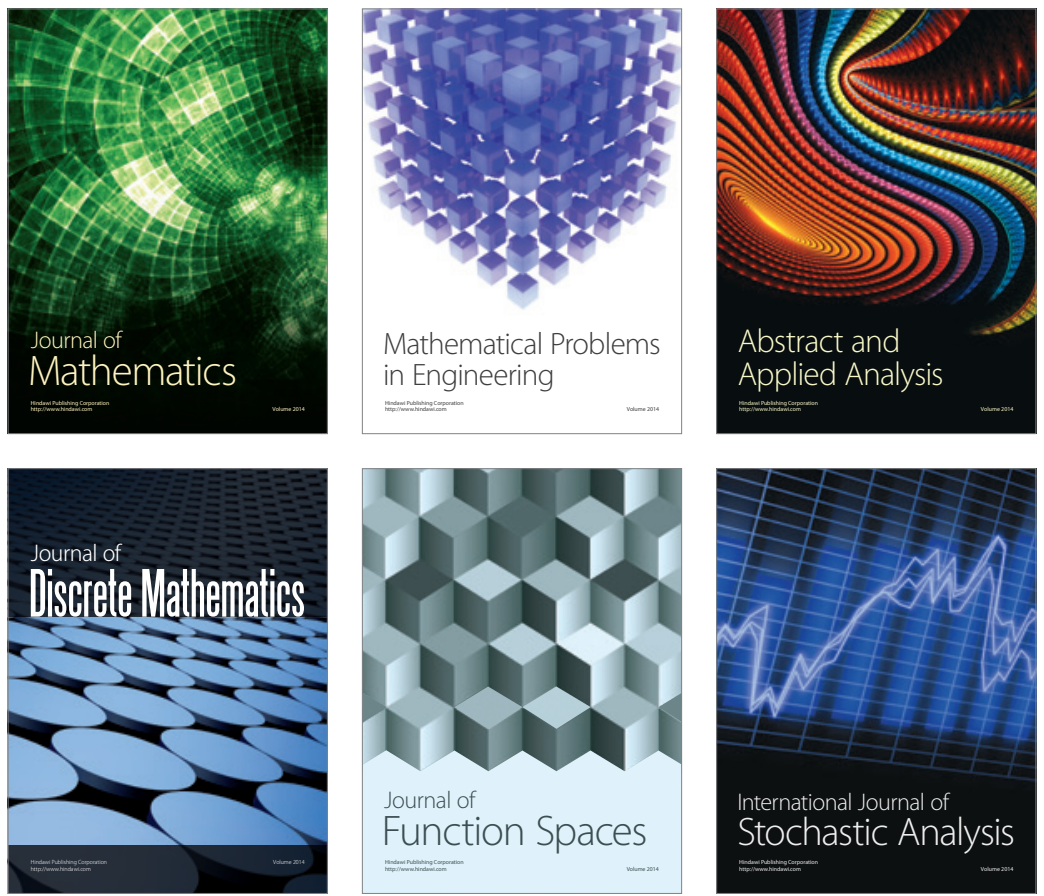

Journal of

Function Spaces

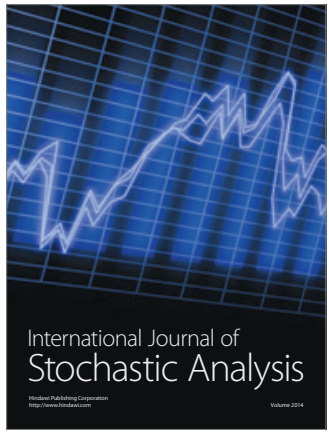

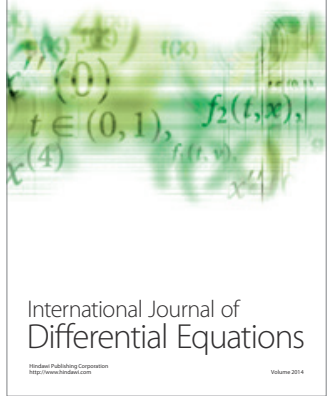
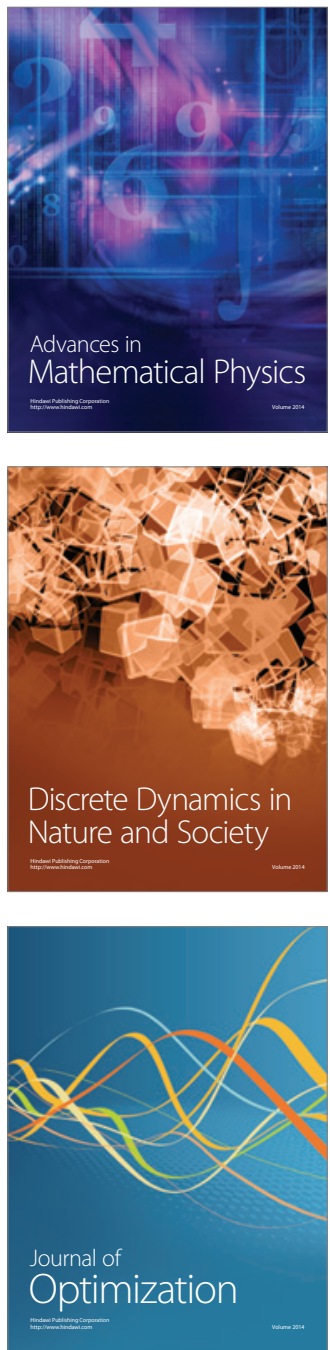